\title{
Vitamin D deficiency and causative factors in the population of Tehran
}

\author{
Sima Hashemipour, Bagher Larijani*, Hossein Adibi, Ebrahim Javadi, \\ Mojtaba Sedaghat, Mohammad Pajouhi, Akbar Soltani, Ali Reza Shafaei, \\ Zohreh Hamidi, Ali Reza Khalili Fard, Arash Hossein-Nezhad and \\ Fargol Booya
}

Address: Endocrinology \& Metabolism Research Center, Tehran University of Medical Sciences, Iran

Email: Sima Hashemipour - emrc@sina.tums.ac.ir; Bagher Larijani* - emrc@sina.tums.ac.ir; Hossein Adibi - emrc@sina.tums.ac.ir; Ebrahim Javadi - emrc@sina.tums.ac.ir; Mojtaba Sedaghat - emrc@sina.tums.ac.ir; Mohammad Pajouhi - emrc@sina.tums.ac.ir; Akbar Soltani - emrc@sina.tums.ac.ir; Ali Reza Shafaei - emrc@sina.tums.ac.ir; Zohreh Hamidi - emrc@sina.tums.ac.ir; Ali Reza Khalili Fard - emrc@sina.tums.ac.ir; Arash Hossein-Nezhad - emrc@sina.tums.ac.ir; Fargol Booya - fargolbooya@yahoo.com

* Corresponding author

Published: 25 August 2004

BMC Public Health 2004, 4:38 doi:10.1 I86/147I-2458-4-38

This article is available from: http://www.biomedcentral.com/I47I-2458/4/38

(c) 2004 Hashemipour et al; licensee BioMed Central Ltd.

This is an open-access article distributed under the terms of the Creative Commons Attribution License (http://creativecommons.org/licenses/by/2.0), which permits unrestricted use, distribution, and reproduction in any medium, provided the original work is properly cited.
Received: 15 October 2003

Accepted: 25 August 2004

\begin{abstract}
Background: There are multiple studies in different countries regarding the prevalence of vitamin $D$ deficiency. These studies showed high prevalence of vitamin $D$ deficiency in Asian countries. This study tries to elucidate the prevalence of vitamin $D$ deficiency and its influencing factors in population of Tehran.
\end{abstract}

Methods: 1210 subjects $20-64$ years old were randomly selected. $25(\mathrm{OH}) \mathrm{D}$ serum levels were measured. Duration of exposure to sunlight, the type of clothing and level of calcium intake and BMI were quantified based on a questionnaire.

Results: A high percentage of vitamin $D$ deficiency was defined in the study population. Prevalence of severe, moderate and mild Vitamin D deficiency was $9.5 \%, 57.6 \%$ and $14.2 \%$ respectively. Vitamin $\mathrm{D}$ serum levels had no significant statistical relation with the duration of exposure to sunlight, kind of clothing and BMI. Calcium intake in the normal vitamin $\mathrm{D}$ group was significantly higher than the other groups $(7 / 4.67 \pm 330.8 \mathrm{mg} /$ day vs $503.39 \pm 303.1,577.93 \pm 304.9,595.84 \pm 3 / 3.6)$. Vitamin $D$ serum levels in young and middle aged females were significantly lower than the older group.

Conclusions: Vitamin D deficiency has a high prevalence in Tehran. In order to avoid complications of vitamin D deficiency, supplemental dietary intake seems essential.

\section{Background}

Vitamin D is an essential element for establishing and maintananing bone structure. Vitamin D deficiency results in rickets and osteomalacia. Even slight vitamin D deficiency results in secondary hyperparathyroidism and increased bone resorption $[1,2]$. In addition, there has 
been increased attention to the physiologic importance of vitamin $\mathrm{D}$ in non-skeletal tissues [3].

Vitamin D is supplied by consumption of vitamin D-rich foods and by vitamin D synthesis in skin.

Natural nutrient materials are not a sufficient source of vitamin D to supply the body requirements; therefore where there is no supplementation of foodstuffs, the main source for vitamin D is produced by UV light $[4,5]$.

Regarding the significant role of sunlight in vitamin D synthesis, it is quite logical to suggest low prevalence of vitamin D deficiency in tropical countries. However the studies carried out in the preceding two decades have shown a high prevalence of vitamin D deficiency in tropical countries such as China, Turkey, India, Iran and Saudi Arabia [6-14]. The prevalence of vitamin D deficiency varied between $30 \%$ and $93 \%$. However, the majority of these studies were limited to specific age and sex groups. Therefore, elucidation of vitamin D status at the community level and in different climates of a country seems essential.

The present study is a part of a national project of prevention, diagnosis and treatment of osteoporosis that investigates the prevalence of vitamin D deficiency and its influencing factors in the population of Tehran.

\section{Methods}

1272 healthy men and women aged 20-69 years were selected based on randomized clustered sampling from 50 blocks in Tehran.

Exclusion criteria were known hepatic or renal disease, metabolic bone disease, malabsorption, sterility, oligomenorrhea, type I diabetes, hypercortisolism, malignancy, immobility for more than one-week, pregnancy, lactation, and medications influencing bone metabolism. The study protocol was approved by research ethics committee of Endocrinology \& Metabolism Research Center (EMRC). Sampling was performed after taking informed consent at the beginning of 2001 in the subjects place of residence. 1210 of 1272 selected subjects participated in this study (response rate was 95\%). One fasting blood sample was taken from each participant in his/her place of residence. Sample centrifuge and serum extraction were done in the field. Then samples were sent to the EMRC laboratory for analysis and were frozen immediately. 25hydroxy vitamin D $(25(\mathrm{OH}) \mathrm{D})$ level was measured with RIA method (Biosource Europes.A,Ò). Normal range for serum vitamin D $(25(\mathrm{OH}) \mathrm{D})$ was 23 to $113 \mathrm{nmol} / \mathrm{l}$. Serum PTH measurement was done using RIA method (Diasorin,Oे). Normal range for PTH is 13 to $54 \mathrm{nmol} / \mathrm{l}$.
Interassay and Intrassy for $25(\mathrm{OH}) \mathrm{D}$ were $8 \%, 6.8 \%$ and for PTH were $8.9 \%$ and $6.1 \%$ respectively.

The subjects were asked to complete a questionnaire at the time of bone mineral densitometry analysis.

The questionnaire included details of duration of exposure to sun light in previous month (less than 30 minutes/ day; between 30 to 60 minutes/day; between 60 to 120 minutes/day; more than 120 minutes/day), sunscreen cream usage, clothing (exposure of hand and face or more than). In order to quantify the level of vitamin D and calcium consumption in the previous month, a food frequency questionnaire which was designed and standard by the Iranian Nutrition Institute was completed. Height and weight were measured at this stage.

25(OH)D equal or less than $12.5 \mathrm{nmol} / \mathrm{l}$ was considered as severe vitamin D deficiency or group 1 and vitamin $\mathrm{D}$ more than $12.5 \mathrm{nmol} / \mathrm{l}$ and less than $25 \mathrm{nmol} / \mathrm{l}$ was considered as moderate deficiency or group 2 [15]. PTH changes in various vitamin $D$ serum levels were applied to detect mild vitamin $\mathrm{D}$ deficiency which has $25(\mathrm{OH}) \mathrm{D}$ more than $25 \mathrm{nmol} / \mathrm{l}$ and less than or equal to $35 \mathrm{nmol} / \mathrm{l}$. Threshold for mild vitamin D deficiency was measured by applying PTH changes in different serum levels of 25(OH) D. SPSS software (version 10) was used for data analysis. In descriptional statistics 5, 50, 95 percentiles were used. Results were expressed as mean \pm SD or median. To find any significant difference between groups, $\mathrm{X}^{2}$ test KruskalWallis were used.

\section{Results}

In order to quantify serum levels of vitamin D and other biochemical parameters, serum samples were taken from 1210 subjects (response rate was $95 \%$ ). $41 \%$ of subjects were male and $59 \%$ were female. Age and sex distribution of participants are shown in table 1. In the second part of study (recall for bone mineral densitometry) for 666 subjects the questionnaire was completed.

Figure 1 demonstrates vitamin D levels histogram in the study population. Total prevalence of severe, moderate and mild vitamin D deficiency was $9.5 \%, 57.6 \%$ and 14.2 $\%$ respectively (Figure 2 ).

Figure 3 demonstrates 95, 50 and 5 percentiles of vitamin $\mathrm{D}$ according to age and sex.

Serum levels of vitamin $\mathrm{D}$ in females above 60 years was higher than in other age groups $(\mathrm{P}<0.001$ : Kruskal-Wallis test). Vitamin D serum levels in females between 20-29 years and 30-39 years was less than other age groups $(\mathrm{P}<$ $0.001)$. Median vitamin $D$ level in females in age range of 
Table I: Age and Sex distribution of participants

\begin{tabular}{cccc}
\hline Age(year) & Total number & Female & Male \\
\hline $\mathbf{2 0 - 2 9}$ & 241 & 128 & 113 \\
$\mathbf{3 0 - 3 9}$ & 308 & 203 & 105 \\
$\mathbf{4 0 - 4 9}$ & 294 & 191 & 103 \\
$\mathbf{5 0 - 5 9}$ & 209 & 116 & 93 \\
$\mathbf{6 0}$ & 158 & 77 & 81 \\
\hline
\end{tabular}

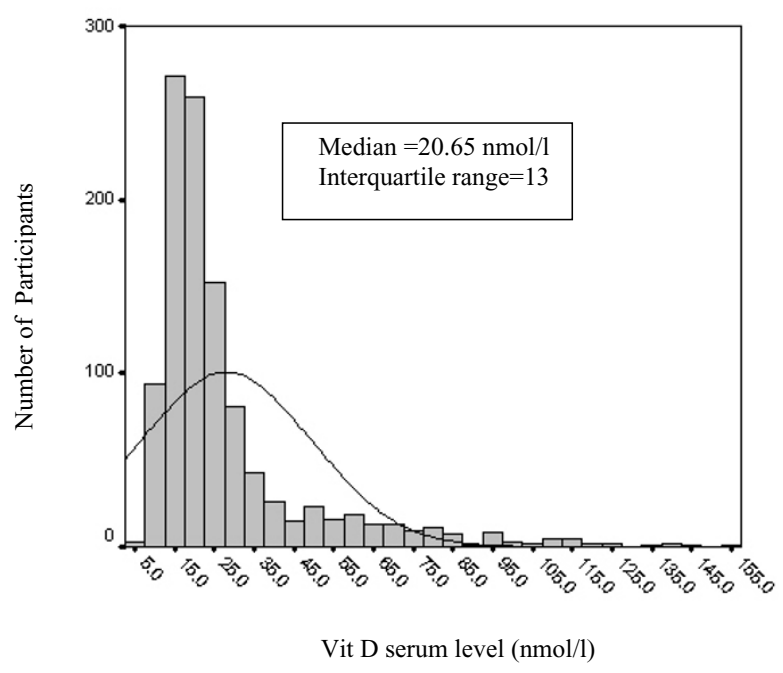

Figure I

Histogram of Vitamin D serum levels in study population

20-29 years and above 60 years was $17 \mathrm{nmol} / \mathrm{l}$ and 39 nmol/l, respectively.

Prevalence of high level of vitamin D (more than 150 $\mathrm{nmol} / \mathrm{l}$ ) in 60-69 years old female age group was significantly more than other age and sex group $(\mathrm{P}<0.01)$. In recalling for bone densitometry, 666 returned (55\% of study population) in whom the effect of influencing factors was evaluated. Table 2 shows mean BMI and daily calcium intake in different vitamin D groups. BMI was not significantly different in vitamin D groups but calcium intake in normal vitamin D group was significantly higher than other groups.

\section{Discussion}

In our study the prevalence of severe and moderate vitamin D deficiency was $9.5 \%$ and $57.6 \%$, respectively. Mild vitamin D deficiency had a prevalence of $14.2 \%$.

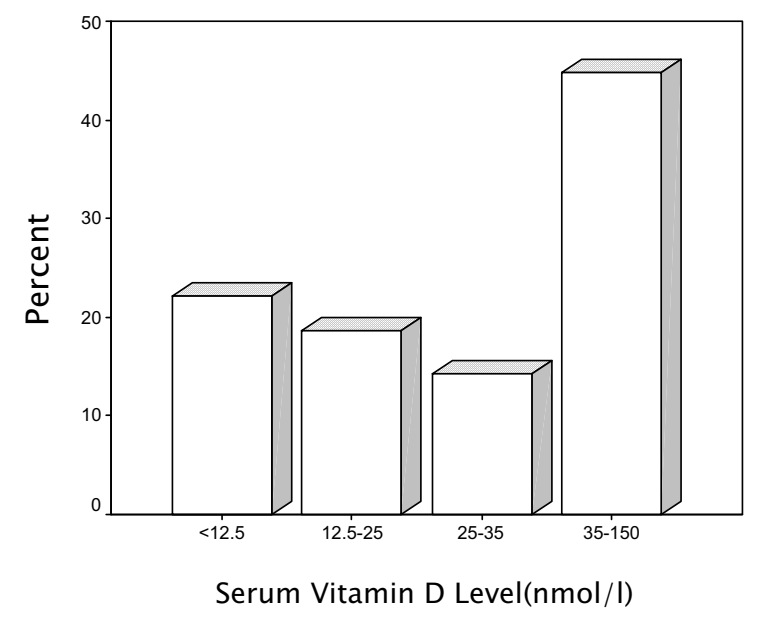

Figure 2

Frequency of variable Vitamin D groups

Multiple studies have been carried out about the prevalence of vitamin D deficiency but they were mostly limited to a small sample size or assessed a specific age group (especially elderly). In countries where vitamin D fortified foodstuffs are available (USA and some Scandinavian countries), prevalence of vitamin D deficiency is between $1.6-14.8 \%$ in different age groups [16-18]. In other European countries where there is no vitamin $\mathrm{D}$ supplementation, deficiency is more prevalent. The studies which assessed middle-aged and elderly people showed vitamin D deficiency prevalence of $14 \%$ to $59.6 \%$ in these age groups [19-22]. Vitamin D deficiency prevalence is much higher in Asian countries.

Fonseca and colleagues, demonstrated vitamin $\mathrm{D}$ level above $10 \mathrm{ng} / \mathrm{ml}$ in only 3 saudian females out of 31 [13]. Sedrani and colleagues showed vitamin D deficiency prev- 
Table 2: Mean BMI and daily calcium intake in variable vitamin D groups

\begin{tabular}{|c|c|c|c|c|}
\hline $\begin{array}{l}\text { Groups } \\
\text { Parameters }\end{array}$ & Vitamin $D \leq I 2.5(\mathrm{nmol} / \mathrm{l})$ & $12.5<$ vitamin $D \leq 25$ & $25<$ vitamin $D \leq 35$ & 35. I<vitamin $D \leq 150$ \\
\hline BMI $\left(\mathrm{kg} / \mathrm{m}^{2}\right)$ & $27.32 \pm 5.02$ & $26.44 \pm 4.52$ & $27.66 \pm 5.16$ & $26.99 \pm 4.93$ \\
\hline Calcium intake (mg/day) & $503.39 \pm 303.1^{*}$ & $577.93 \pm 304.9^{*}$ & $595.84 \pm 313.6^{*}$ & $714.67 \pm 330.8$ \\
\hline
\end{tabular}

*Significant difference with normal group $(35.1<$ vitamin $D \leq 150) P<0.05$

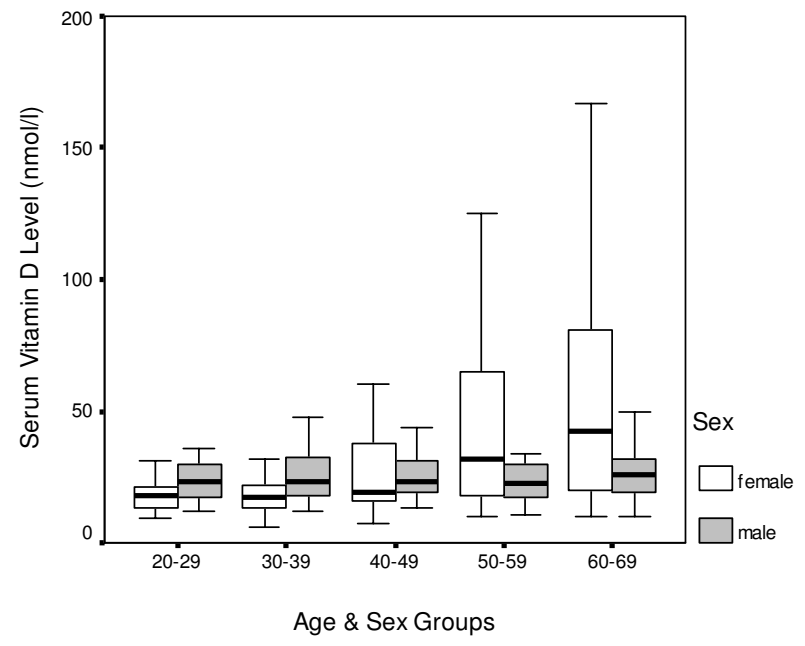

Figure 3

Median, 5, and 95 percentile of Vitamin D in variable age and sex groups

alence of $44 \%-100 \%$ in Saudian young females with different coverage and race $[9,10]$. Azizi \& colleagues showed vitamin D level less than $18 \mathrm{ng} / \mathrm{ml}$ in half of the study population. Vitamin D deficiency prevalence in 10$19,20-24,30-41$ was $47.4 \%, 59.5 \%, 44.8 \%$ respectively [11]. In the present study $81.3 \%$ of subjects had vitamin D deficiency.

Most studies have shown higher prevalence of vitamin D deficiency in the elderly [15-18]. Elderly females demonstrated statistically significant higher serum levels of vitamin $\mathrm{D}$ compared with young and middle aged females. Parenteral vitamin D intake by elderly was the major differentiating factor between various age groups that could explain high prevalence of a high level of vitamin D in elderly females.
Subjects who took vitamin D in the sampling period were excluded from the study, but those who had taken vitamin $\mathrm{D}$ in the preceding months were not omitted. Vitamin D has a long half-life and its frequent prescription especially in elderly women with musculo-skeletal complaints can explain differences in serum vitamin D. Regarding the essential role of sunlight in vitamin D synthesis, it is quite unexpected to see a high prevalence of vitamin D deficiency in countries such as Saudi Arabia. Different hypotheses can be made such as insufficient sun exposure, clothing habits, hyper pigmentation, air pollution, insufficient intake of vitamin D and special dietary habits [27]. Although sunlight plays an essential role in vitamin D synthesis, its' role in vitamin D deficiency of Asians is not obvious. Tehran, which is located in $36^{\circ} 21^{\prime \prime} \mathrm{N}$, has a mean sun exposure of 8 hours per day [28].

In the present study sun exposure was not significantly different between subjects with vitamin D deficiency and those with normal vitamin D status.

Although there is sufficient sunlight in all seasons in Saudi Arabia, Sedrani showed that half of people who had more than 30 minutes of sun exposure had vitamin D less than $8 \mathrm{ng} / \mathrm{ml}$ (20 nmol/l) [10]. Holick \& colleagues showed similar rate of vitamin D synthesis in Asians as of Europeans; but Asians required greater duration of exposure [29]. Other studies showed the same degree of increase in 25 $(\mathrm{OH}) \mathrm{D}$ in summer months in Asians compared with Europeans [30]. In our study, there was no difference in clothing habits of vitamin D deficient group and normal group.

Sedrani showed 70\% vitamin D deficiency in males compared with $30 \%$ in young females in spite of greater clothing in females [10].

Another hypothesis says that air pollution prevents enough UV exposure to skin. Insufficient vitamin D intake is another hypothesis for high prevalence of vitamin D deficiency in Asians.

Insufficient dietary supplies of vitamin D in countries where foodstuffs are not supplemented, leads to generally low dietary intake of vitamin D. In the Omdahl study, 
daily vitamin D intake in elderly healthy women was 54 units [16]. Our study does not assess daily dietary vitamin $\mathrm{D}$ intake. Decreased dietary calcium level induces increased serum PTH level and increased catabolism of 25 $(\mathrm{OH}) \mathrm{D}$, therefore decreased $25(\mathrm{OH}) \mathrm{D}$ is induced by dietary calcium deficiency [15].

Average calcium intake was $660 \pm 350 \mathrm{mg} /$ day in this study. There was no significant difference in dietary calcium intake among the different vitamin D groups. Although consumption of phytates and animal-derived proteins was not investigated in present study, high dietary consumption of phytates and low dietary intake of animal proteins is one of the suggested hypothesis for vitamin D deficiency $[24,26,27]$.

There are other hypotheses to explain vitamin D deficiency among Asians. Awumey et al showed higher activity level of 24-hydroxylase in fibroblasts of IndianAmericans compared with controls [31]. Therefore, increased vitamin D catabolism may cause vitamin D deficiency in Asians. In order to elucidate specific etiologies responsible for high prevalence of vitamin $\mathrm{D}$ deficiency in Asians further studies should be carried out. It is possible that vitamin $\mathrm{D}$ deficiency is induced by combination of above mentioned etiologies. In order to clarify the significance of each etiologic factor, randomized controlled trials are necessary.

\section{Conclusions}

Given the high prevalence of vitamin D deficiency in Iran, effective solution to overcome its consequences seems indispensable.

\section{Competing interest}

None declared.

\section{Acknowledgments}

The authors are thankful to Dr. Fatemeh Bandarian and Dr. Seyed Mohammad Akrami for their efforts in preparing this article and to EMRC laboratory staff for their continuous co-operation.

\section{References}

I. Parfitt AM, Gallagher JC, Heaney RP, Johnston CC, Neer R, Whedon GD: Vitamin $\mathbf{D}$ and bone health in the elderly. Am J Clin Nutr |982, Suppl 5: 1014-1031.

2. Peacoak M: Effect of calcium and vitamin $D$ insufficiency on the skeleton. Osteoporos Int 1998, Suppl 8:S45-S5I.

3. Deluca HF: The Vitamin D Story: a Collaborative effort of basic science and clinical medicine. FASEB 1988, 2:224-236.

4. Bouillon R: Vitamin D: Photosynthesis, metabolism, and action to clinical applications. In Endocrinology 3rd edition. Edited by: Degroot L, Jameson JL, Burger HG. Philadelphia: WB Saunders; 2001:1009-1028.

5. Bouillon R, Carmeliet G, Daci E, et al.: Vitamin D Metabolism and action. Osteoporos Int 1998, Suppl 2:SI3-19.

6. Du X, Greenfield H, Fraser DR, et al.: Vitamin D deficiency and associated factors in adolescent girl in Beijing. Am J Clin Nutr 200I, 74:494-500.

7. Alagol F, Shihadeh Y, Boztepe H, et al.: Sunlight exposure and vitamin D in Turkish women. J Endocrinol Invest 2000, 23: I73-I77.
8. Dawodu A, Agarwal M, Hossain M, et al.: Hypervitaminosis D and vitamin $D$ deficiency in exclusively brest feeding infants and their mother in summer :a justification for vitamin $D$ supplementation of brest-feeding infants. J Pediatr 2003, I 42: I69-173.

9. Sedrani SH: Low 25-Hydroxy vitamin $D$ and normal serum calcium concentrations in Saudi Arabia: Riyadh region. Ann Nutr Metab 1984, 28:18|-I85.

10. Sedrani SH, Elidrissy AW, Arabi KM: Sunlight and vitamin D status in normal Saudi subjects. Am J Clin Nutr I983, 38: I29-I 32.

II. Azizi F, Rais-Zadeh F, Mir Said Ghazi A: vitamin D deficiency in a group of Tehran Population. Research In Medicine 2000, 4:291-303.

12. Taha S, Dost S, Sedrani S: 25-hydroxy vitamin D and total calcium extra ordinarily low plasma concentrations in Saudi mothers and their neonates. Pediatr Res 1984, I 8:739-74I.

13. Fonseca V, Tongia R, el-Hasmi M, et al.: Exposure to sunlight and vitamin D deficiency in Saudi Arabian women. Postgrad Med J 1984, 60:589-59|.

14. Gowami R, Gupta N, Gosuwami D, et al: Prevalence and significance of low 25-Hydroxy vitamin $D$ concentrations in healthy subjects in Dehli. Am J Clin Nutr 2000, 72:422-475.

15. Lips P: Vitamin D deficiency and secondary hyperparathyroidism in the elderly: Consequences for bone loss and fractures and therapeutic implications. Endocr $\operatorname{Rev} 2001$, 22:477-50I.

16. Omdahl JL, Garry PJ, Hunsaker LA, et al.: Nutritional status in a healthy elderly population: vitamin D. Am J Clin Nutr 1982, 36: $1225-1232$.

17. Kinyamu HK, Gallagher JC, Balhorn KE, et al.: Serum vitamin D metabolites and calcium absorpation in normal young and elderly free - living women and in women living in nursing homes. Am J clin Nutr 1997, 65:790-797.

18. Burnard B, Sloutskis D, Gianoli F, et al.: Serum 25-Hydroxy vitamin D: distribution and determinants in the Swiss population. Am J Clin Nutr 1992, 56:537-542.

19. Chapuy MC, Preziosi P, Maamer M, et al.: Prevalence of vitamin D insufficiency in on adult normal population. Osteopros Int 1997 , 7:439-443.

20. Scharla SH, Scheidt Nave C: Reference range of 25-Hydroxys vitamin D serum concentrations in Germany. Clin Lab 1996, 42:475-477.

21. Vander Wielen RP, Lowik MR, Vanden Berg H, et al.: Serum vitamin D concentrations among elderly people in Europe. Lancet 1995, 346:207-210.

22. Souberbielle JC, Cormier C, Kindermans C, et al.: Vitamin D status and redefining serum parathyroid hormone reference range in the elderly. J clin Endocrinol Metab 200I, 86:3086-3090.

23. Bettica $P$, Bevilacqua $M$, Vago $T$, Norbiato $G$ : High prevalence of hypovitaminosis among free living postmenopausal women referred to an osteoporos outpatient clinic in northern Italy for initial screening. Osteoporosis Int 1999, 9:226-229.

24. Finch PJ, Ang L, Colston KW, et al.: Blunted Seasonal variation in serum 25-hydroxy vitamin $D$ and increased risk of osteomalacia in vegetarian London Asians. Eur J clin Nutr 1992, 46:509-5I5.

25. Goel KM, Sweet EM, Logan RW, et al.: Florid and subclinical rickets among immigrant children in Glasgow. Lancet 1976, I:I|4|-I|45.

26. Reinhold JG: Rickets in Asian immigrants. Lancet 1976, 2:II32-II33.

27. Smith R: Asian rickets and osteomalacia. Q J Med 1990, 76:899-901.

28. National statistics directory book.. Iran Statistics Center: Number in publications of statistics center. 2001:3589.

29. Lo CW, Paris PW, Holick MF, et al.: Indian and Pakistani immigrants have the same capacity as Caucasians to produce vitamin D in response to ultra violet irradiation. Am J Clin Nutr 1986, 44:683-685.

30. Hunt SP, O'Riodan JL, Windo J, et al.: Vitamin D status in different subgroups of British Asians. BMJ 1976, 2: I35 I-I354.

31. Awumey EM, Mitra DA, Hollis BW, et al.: Vitamin D metabolism is altered in Asian Indians in the southern United States: a clinical research study. J Clin Endocrinol Metab 1998, 83:I69-I73. 


\section{Pre-publication history}

The pre-publication history for this paper can be accessed here:

http://www.biomedcentral.com/1471-2458/4/38/prepub

Publish with Biomed Central and every scientist can read your work free of charge

"BioMed Central will be the most significant development for disseminating the results of biomedical research in our lifetime. " Sir Paul Nurse, Cancer Research UK

Your research papers will be:

- available free of charge to the entire biomedical community

- peer reviewed and published immediately upon acceptance

- cited in PubMed and archived on PubMed Central

- yours - you keep the copyright 